Original Research Article

\title{
Study of drug prescription pattern in ischemic heart disease patients
}

\author{
Mahadeo P. Sawant, Sudhir L. Padwal*, Rakesh R. Jadhav, Harshal N. Pise, Rucha Shinde
}

Department of Pharmacology, S.R.T.R. Government Medical College, Ambajogai,

Maharashtra, India

Received: 03 May 2019

Accepted: 31 May 2019

*Correspondence to:

Dr. Sudhir L. Padwal

Email: drsudhirp.77@gmail.com

Copyright: (C) the author(s), publisher and licensee Medip Academy. This is an openaccess article distributed under the terms of the Creative Commons Attribution NonCommercial License, which permits unrestricted noncommercial use, distribution, and reproduction in any medium, provided the original work is properly cited.

\begin{abstract}
Background: Drug utilization pattern studies helps to screen, assess and propose appropriate modifications in prescription practices, this would help to make patient care rational and cost effective. Study was intended to analyse the drug prescribing pattern for treatment of Ischemic heart disease using WHO indicators. Methods: This is a cross sectional observational study conducted on ischemic heart disease patients admitted at inpatient department of medicine in a tertiary care teaching hospital. The study consisted of analysis of drug utilization pattern of prescribed drugs.
\end{abstract}

Results: IHD was more commonly seen in males $(70.06 \%)$ than females (29.94\%). IHD was most commonly seen in patients of age group of 61-70 year. Drugs prescribed to patients belong to various therapeutic classes ranging from anti-platelets, anticoagulants, anti-anginal, antithrombin, thrombolytic, hypolipidemics. The most commonly prescribed therapeutic class of drugs was antiplatelet $(86.26 \%)$ followed by hypolipidemic $(82.25 \%)$ and ACE inhibitors drugs $(46.60 \%)$. Average number of drugs per encounter was 7.70. Drugs were prescribed by their generic names were $29.99 \%$. Out of total study group $22.06 \%$ patients were prescribed at least one antibiotic. Injections were prescribed only in $1392(27.86 \%)$ out of 4995 drugs. Of total drugs $3270(65.45 \%)$ of drugs were from National List of Essential Medicines-2016 (NLEM -2016) and 2774 $(55.53 \%)$ drugs prescribed were from WHO-EML-2016.

Conclusions: Risk of artery disease increased with increasing age. IHD was more common in males than females. The most commonly prescribed drug classes in Ischemic heart disease were anti-platelet drugs followed by hypolipidemic agents.

Keywords: Anticoagulants, Antiplatelet, ACE inhibitors, Drug utilization, Hypolipidemics, Ischemic heart disease

\section{INTRODUCTION}

Ischemic heart disease (IHD) is a condition in which there is an inadequate supply of blood and oxygen to a portion of the myocardium, it occurs if there is imbalance between myocardial oxygen supply and demand. The common cause of myocardial ischemia is atherosclerosis of epicardial coronary artery/arteries which leads to regional reduction in myocardial blood flow and inadequate perfusion of the myocardium supplied by the involved coronary artery. ${ }^{1}$
Ischemic heart disease (IHD) is one of the leading causes of mortality and it is also a primary cause of premature mortality and disability in developing countries like India. ${ }^{2}$ Noncommunicable diseases (NCDs) kill 40 million people each year, equivalent to $70 \%$ of all deaths globally. Each year, 17 million people die from a NCD before the age of seventy, and 87 percentages of premature deaths occur in low and middle-income countries. Cardiovascular diseases account for most non-communicable diseases deaths, (17.7 million population yearly) which is followed by cancers (8.8 million), respiratory diseases (3.9 million), and diabetes (1.6 million). ${ }^{3}$ 
The World Health Organization (WHO) and Global Burden of Disease Study also have highlighted increasing trends in years of life lost (YLLs) and disability-adjusted life years (DALYs) from IHD in India. In India, studies have reported increasing IHD prevalence over the last 60 years, from $1 \%$ to $9 \%-10 \%$ in urban populations. ${ }^{4}$ Striking features of IHD epidemiology in India are high mortality rates, premature $\mathrm{CHD}$, and increasing burden. ${ }^{5}$ Among the causes for this rising burden, the upcoming pandemic of obesity and diabetes further enhances the estimates of $\mathrm{CV}$ mortality and healthcare costs over the next decades.

Despite the stress on primary prevention, $\mathrm{CV}$ risk factors are still poorly. In chronic conditions such as hypertension, ischemic heart disease (IHD) and cardiac failure, the progressive use of multiple drugs is common. Polypharmacy is associated with an increased morbidity with increasing in the costs. Prescribing multiple drugs often leads to inappropriate utilization of drugs, lower adherence to treatment and increase in chances of side effects.

The risk factors for ischemic heart disease include dyslipidemia (high apolipo-protein B / apolipo-protein A1 ratio), tobacco use, smoking, hypertensive and /or diabetic patients, obese, physical sedentariness, lowfruits and vegetable intake, and stress. ${ }^{6}$ Drugs play important role in promoting health of patients who are seeking treatment for various ailments, however to get these desired effects drugs should be safe and efficacious. Drugs must be utilized judiciously.

Drug utilization pattern studies helps to screen, assess and propose appropriate modifications in prescription practices; this would help to make patient care rational and cost effective. Rational drug prescribing is defined patients receive medications appropriate to their clinical needs, in doses that meet their own individual requirements, for an adequate period of time, and at the lowest cost to them and their community. ${ }^{7}$

Drug utilization studies are influential aid to ascertain the role of drug in the society. The World Health Organization (WHO) has defined drug utilization research as the marketing, distribution, prescription and use of drugs in a society, with special emphasis on the resulting medical, social and economic consequences. ${ }^{8}$ Drug therapy is available often at an unaffordable price. Hence, it is very important to realize that dispensing inappropriate and irrational drugs for treatment of various disease leads to potential hazards. ${ }^{9}$ It is globally a major concern. So it is very important to review the drug utilization pattern periodically, to ensure its safety and efficacy. ${ }^{10}$

World Health Organization (WHO) and International Network of Rational Use of Drugs (INRUD) have provided guidelines of rational drug use. When applied, these indicators give fair idea about prescription pattern, availability of drugs and patients comprehension about therapy. It helps to overcome the shortcoming and enhance the performance from day to day. ${ }^{11}$ Indiscriminate use of drugs in ischemic heart disease patient may lead increased adverse events. Still, very scanty data is available regarding drug utilization pattern in Ischemic heart disease treatment. In the given circumstances, present study is proposed to investigate prescription and drug utilization practices in ischemic heart disease patients admitted in Medicine ward in a government tertiary care hospital in Maharashtra.

\section{METHODS}

\section{Methodology}

This is a cross sectional observational study conducted on ischemic heart disease patients admitted at inpatient department of Medicine in a tertiary care teaching hospital.

The study consisted of analysis of drug utilization pattern of prescribed drugs.

\section{Study population}

All ischemic heart disease patients admitted in medicine inpatient department were enrolled in the study as per the following inclusion and exclusion criteria over a period of January 2016-June 2017.

\section{Inclusion criteria}

All diagnosed cases of in-patients with ischemic heart disease during the study period (January 2016- June 2017).

\section{Exclusion criteria}

- Patient not willing to consent for the study

- Outpatients Department (OPD) patients

- Patients who were under day care management

\section{Statistical analysis}

The statistical analysis was done with the help of Microsoft Excel 2010 software.

\section{RESULTS}

\section{Demographic data}

Around 648 patient's data, who were admitted during Jan2016 to June 2017, was collected and analyzed. The demographic data is shown in Figure 1 as follows.

IHD was more commonly seen in males $(70.06 \%)$ than females (29.94\%). IHD group patients were divided according to age in 7 classes. As per study analysis, IHD was most commonly seen in patients of age group of 61-70 year. The mean age of study group was 65.32 Years. (Age wise details are as shown in (Table 1). 


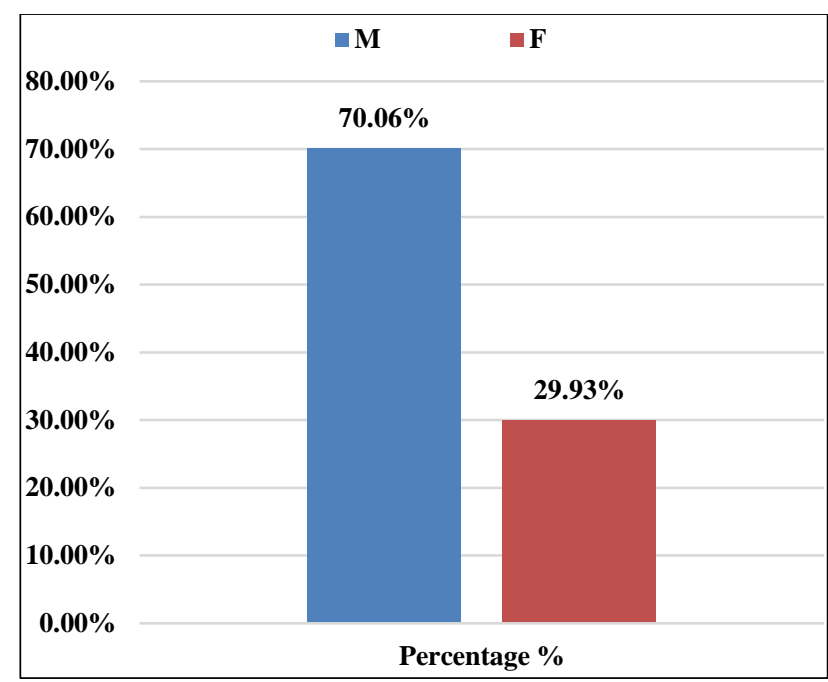

Figure 1: Gender wise distribution of patients

Table 1: Age group wise distribution of patients.

\begin{tabular}{|lll|}
\hline Age group & Number & Percentage $(\%)$ \\
\hline $20-30$ Yrs & 9 & $1.38 \%$ \\
\hline$>30-40$ Yrs & 21 & $3.24 \%$ \\
\hline$>40-50$ Yrs & 76 & $11.72 \%$ \\
\hline$>50-60$ Yrs & 124 & $19.13 \%$ \\
\hline$>60-70$ Yrs & 278 & $42.90 \%$ \\
\hline$>70-80$ Yrs & 108 & $16.66 \%$ \\
\hline$>80$ Yrs & 32 & $4.93 \%$ \\
\hline
\end{tabular}

Total 4995 drugs were prescribed to 648 patients of Ischemic heart disease during our study. The number of drugs ranged from 4-14 per patient with average of 7.70 drugs per patient. (Table 2).

Table 2: Number of drugs prescribed per prescription.

\begin{tabular}{|lll|}
\hline No. of drugs & $\begin{array}{l}\text { No. of } \\
\text { prescriptions }\end{array}$ & $\begin{array}{l}\text { Percentage } \\
(\%)\end{array}$ \\
\hline 4 & 13 & $2.00 \%$ \\
\hline 5 & 42 & $6.49 \%$ \\
\hline 6 & 67 & $10.35 \%$ \\
\hline 7 & 145 & $22.41 \%$ \\
\hline 8 & 167 & $25.81 \%$ \\
\hline 9 & 106 & $16.38 \%$ \\
\hline 10 & 79 & $12.21 \%$ \\
\hline 11 & 25 & $3.86 \%$ \\
\hline 12 & 2 & $0.30 \%$ \\
\hline 14 & 1 & $0.15 \%$ \\
\hline
\end{tabular}

Drugs prescribed to patients belong to various therapeutic classes ranging from anti-platelets, anticoagulants, antianginal, antithrombin, thrombolytic, hypolipidemics. The most commonly prescribed therapeutic class of drugs was anti-platelet $(86.26 \%)$ followed by hypolipidemic $(82.25 \%)$ and ACE inhibitors drugs (46.60\%). Mostly commonly prescribed drug was clopidogrel (86.26\%) followed by atorvastatin (82.5\%), aspirin (82.09\%), enalapril (46.60\%), asosorbide dinitrate $25.92 \%$, furosemide (P) 20.84\%, metoprolol 12.96\%, Amlodipine $10.33 \%$, Furosemide $4.93 \%$, digoxin $3.3 \%$, atenolol $1.85 \%$. (Figure 2).

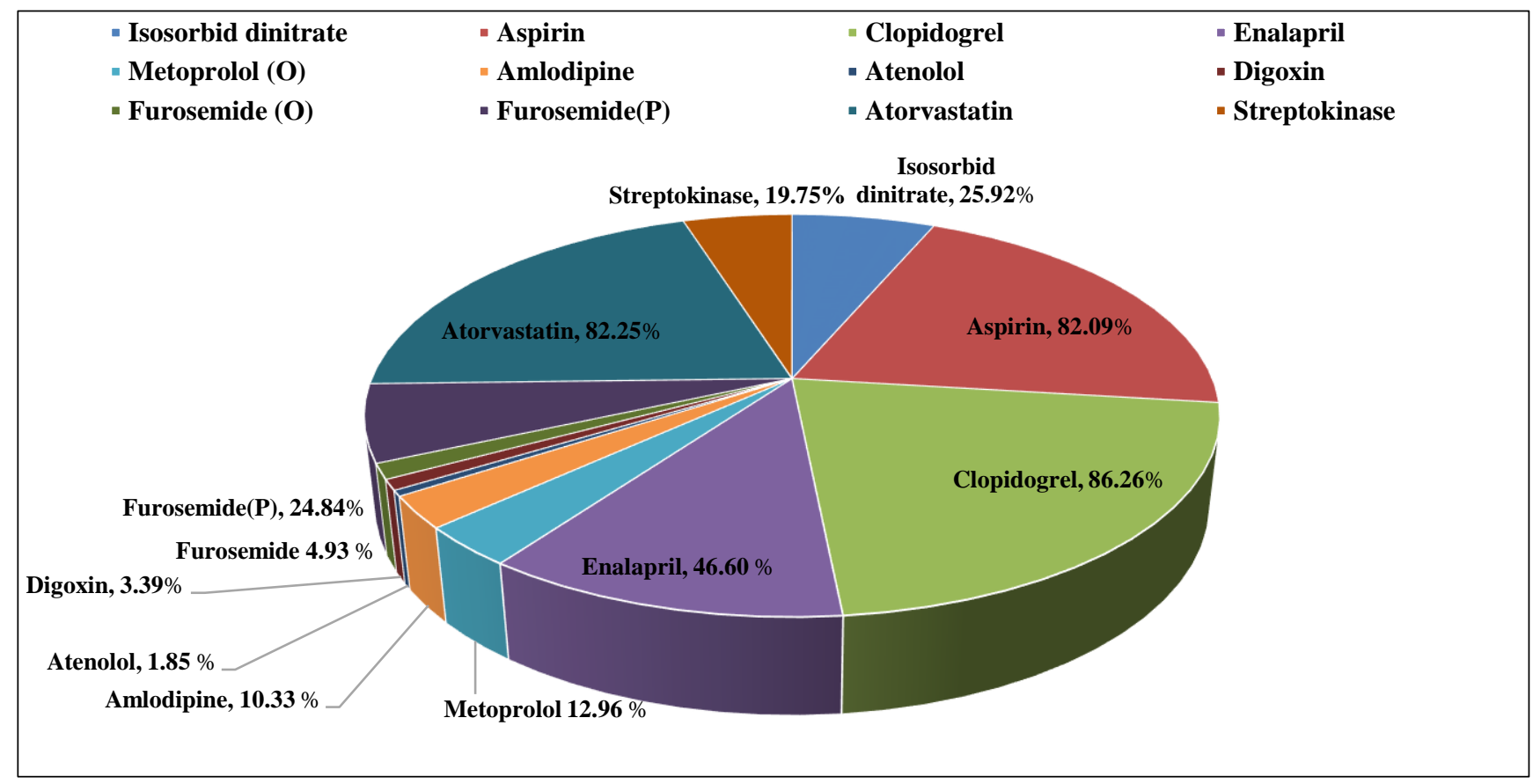

Figure 2: Percentage of drugs prescribed as per drug class. 
Out of total 4995 of drugs prescribed, maximum drugs $71.19 \%$ were prescribed in oral formulations. (Figure 3) followed by intravenous (22.95\%) and subcutaneous (4\%), as shown in Figure 3.

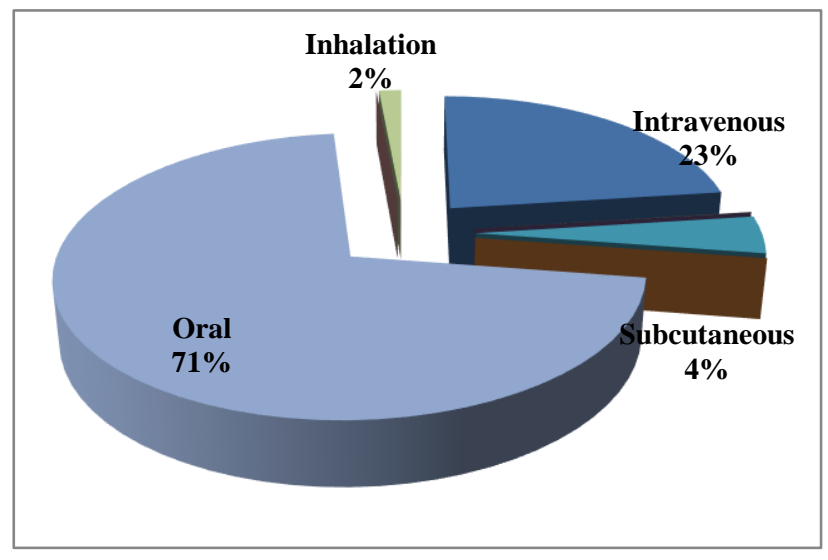

Figure 3: Various routes of drug administration WHO core drug use indicators.

\section{Prescribing indicators}

- Average number of drugs per encounter

- Total of 4994 drugs were prescribed to 648 patients. So, average number of drugs per encounter was 7.70. Out of total 4995 of drugs prescribed, maximum drugs $71.19 \%$ were prescribed in oral formulations

- Percentage of drugs prescribed by generic names

- In previous studies reviewed, prescribing drugs with brand names was commonly observed practice. In current study prescription analysis showed that 1498 (29.99\%) drugs were prescribed by their generic names

- Percentage of encounters with antibiotics prescribed:

- In present study, antibiotics were prescribed to few patients. Out of 648 prescriptions, $143(22.06 \%)$ were having at least one antibiotic

- Percentage of encounters with injections prescribed Injections were prescribed only in 1004 (26.89\%) out of 4995 drugs

- Percentage of drugs prescribed from essential drug list or formulary

- Of total drugs 3270 (65.45\%) of drugs were from National List of Essential Medicines -2016 (NLEM 2016) and $2774(55.53 \%)$ drugs prescribed were from WHO-EML-2016

\section{DISCUSSION}

Drug utilization studies are useful to determine the behavior of the use of medicines in a society. ${ }^{12}$ Since past few years many research drug utilization studies are being performed worldwide to assess and to understand the safe and more effective drug utilization, these studies are indicating that irrational drug use is a universal phenomenon. Countries like India are becoming global epicenter for various diseases like ischemic heart disease and diabetes. Hence, it is the need of the time to decrease the risk factors and to improve the treatment strategies for these diseases. $^{12}$

Around 648 patient's prescriptions were analyzed from medicine ward for 18 months. Study results indicated that male $(70.06 \%)$ patients had a high frequency of ischemic heart disease incidences as compared to female (29.94\%) patients which were in accordance to Nagabushan $\mathrm{H}$. et al, and Sreedevi K et al. ${ }^{13,14}$ As per Dawalji S et al, 72.94\% patients were male and $27.06 \%$ were female as per other study by Tamilselvan $\mathrm{T}$ et al, $69.1 \%$ accounts for males and $30.8 \%$ accounts for females as per Sreedevi K et al, gender-wise distribution showed males $61.5 \%$ predominance, whereas, females were $38.5 \% .^{14,15,16}$ Whereas, similar study by Shankar R et al, showed the female $(51.94 \%)$ predominance over males $(48.06 \%) .{ }^{17}$ The study results were found to be consistence with most of the previous studies and indicated that male are more prone to coronary artery disease as compared to female.

\section{WHO core drug use indicators}

\section{Average number of drugs per prescription}

In current study, the number of drugs prescribed ranged from four to fourteen per patient. So, average number of drugs per prescription was 7.70. It is comparable to the average number of drugs prescribed in the studies of Nagabushan H et al, (7.8). ${ }^{13}$ It is much less as compared to the findings of Sandozi T et al, (9.93) and little higher than Shankar R et al, 3.39 drugs per patients. ${ }^{17,18}$

This difference can be due to variation in drug prescription habits and patient need and sometimes choice of patients.

\section{Percentage of drug prescribed by generic names}

In this study, data analysis showed that 1498 (29.99\%) drugs were prescribed by with generic names. In study by Nagabushan $\mathrm{H}$ et al, drugs prescribed by their generic names were $52.9 \%$ which is higher than present study while in the study of Sandozi T et al, were 6\%. ${ }^{13,19}$ This is much less as compared to present study. Similar findings were reported in study Shankar $\mathrm{R}$ et al, $(36.43 \%) .{ }^{17} \mathrm{~A}$ prescription could be considered as appropriate if prescribed in the form of generic drugs. This would help in reducing the cost of treatment for the patients. It also helps in decrease prescription writing errors and confusion in dispensing of different brand names which sound alike and/or spell similar.

\section{Percentage of encounters with antibiotics}

In present study, antibiotic is one of the prescribed therapeutic classes of drugs. Out of 648 prescriptions, 143 $(22.06 \%)$ were having at least one antibiotic. This finding is much lower than the similar studies by, Christain RP et al, 37.9\%, Nagabushan $\mathrm{H}$ et al, 40.20\%, Dawalji S et al, $92.94 \%$, and higher than the study by Tamilselvan $\mathrm{T}$ et al, 
$163.20 \% \cdot \cdot^{13,15,16,19}$ This is in accordance to WHO recommendation for use of minimum required antibiotics, which helps to decrease the polypharmacy, decrease chances of developing resistance, and adverse drug reactions

\section{Percentage of encounters with injections}

In this study, injections were prescribed only in 1392 $(27.86 \%)$ out of 4995 drugs. In a similar study of Nagabushan $\mathrm{H}$ et al, $100 \%$ drugs were given by injections. ${ }^{13}$ These findings are in contrast with those of studies of Shankar R et al,were injectable preparations used for only $7.89 \%$ of drugs. ${ }^{17}$ Lower usage of injectable drugs is in accordance WHO recommendations as oral route is safer than injections.

\section{Percentage of drugs prescribed from National List of} Essential Medicines (NLEM)

In this study, out of total 4995 drugs, 3270 (65.45\%) of drugs were from National List of Essential Medicines (NLEM) and 2774 (55.53\%) drugs prescribed were from World Health Organization Essential Medicines List (WHO-EML). Some other similar studies cited in the literature e.g. Nagabushan $\mathrm{H}$ et al, $75.1 \%$ and Shankar R et al, $60.32 \%$ drugs were prescribed from WHO-EML. ${ }^{13,17}$ Higher percentage of prescribed drugs from NLEM may be indicative of rational prescribing. Adherence to NLEM for drug prescription not only promotes the rational use of medicines but also optimize the available health resources of a country.

This study had few limitations. It was conducted at a single tertiary healthcare centre. Studies with data from multicentric group of population in similar context would give additional information on this aspect. This study population was relatively homogenous. Hence, this study results may not be generalized to other population. It was a quantitative type of drug prescribing pattern study with the WHO core prescribing indicators and therefore determining the quality of diagnosis and the appropriateness of treatment was beyond scope of prescribing indicators.

Funding: No funding sources Conflict of interest: None declared

Ethical approval: The study was approved by the Institutional Ethics Committee

\section{REFERENCES}

1. Antma EM, Selwyn AP, Loscalzo J. Ischemic Heart Disease. Harrison's Principles of Internal Medicine. $18^{\text {th }}$ ed. New York: McGraw-Hill; 2012:1998-2015.

2. World Health Organisation. Miscoding and misclassification of ischaemic heart disease mortality. World Health Organisation; 2001. Available at http://www.who.int/healthinfo/paper12.pdf. accessed 18 Feb 2017.
3. World Health Organisation. Fact Sheet. The top 10 causes of death. World Health Organisation; 2001. Available http://www.who.int/mediacentre/factsheets/fs310/en/.

4. Gupta R, Mohan I, Narula J. Trends in Coronary Heart Disease Epidemiology in India. Ann Glob Heal Elsevier Inc. 2016;82(2):307-15.

5. Gupta R, Guptha S, Sharma KK, Gupta A, Deedwania PC. Regional variations in cardiovascular risk factors in India: India heart watch. World J Cardiol. 2012 26;4(4):112.

6. Gupta R, Mohan I, Narula J. Trends in coronary heart disease epidemiology in India. Ann Glob Heal Elsevier Inc. 2016;82(2):307-15.

7. World Health Organisation. The Pursuit of Responsible Use of Medicines. World Health Organisation; 2012. Available at http://www.who.int/medicines/areas/rational_use/en/. Accessed 26 Feb 2017.

8. World Health Organization (WHO) and International Network for Rational Use of Drugs, How to Investigate Drug Use in Health Facilities: Selected Drug Use indicators, WHO/DAP/93.1, WHO, Geneva, Switzerland, 1993. Available at http://apps.who.int/medicinedocs/pdf/s2289e/s2289e. pdf. Accessed 27 Feb 2017.

9. Hawkey CJ, Hodgson S, Norman A, Daneshmend TK, Garner ST. Effect of reactive pharmacy intervention on quality of hospital prescribing. BMJ. 1990 ;300(6730):986-90.

10. World Health Organization (WHO) International Working Group for Drug Statistics Methodology, WHO Collaborating Centre for Drug Statistics Methodology, WHO Collaborating Centre for Drug Utilization Research and Clinical Pharmacological Services. Introduction to Drug utilization Research, WHO, Oslo, Norway, 2003. Available at http://apps.who.int/medicinedocs/pdf/s4876e/s4876e. pdf. Accessed 3 Mar 2017.

11. World Health Organization (WHO. Guidelines for ATC Classification and DDD assignment 2013. Available https://www.whocc.no/filearchive/publications/1_201 3 guidelines.pdf. Accessed 3 Mar 2017.

12. Introduction to Drug Utilization Research. World Health Organization 2003. Available at http://apps.who.int/medicinedocs/pdf/s4876e/s4876e. pdf. Accessed 18 Feb 2017.

13. Nagabushan H, Roopadevi HS, Prakash GM, Pankaja R. A prospective study of drug utilization pattern in cardiac intensive care unit at a tertiary care teaching hospital. Inter J Basi Clin Pharma. 2017;4(3):579-83.

14. Sreedevi K, Rao JV, Fareedullah M, Vijayakumar S. A study on prescription pattern of statins in cardiovascular disease. Der Pharm Lett. 2011;3(3):393-6.

15. Dawalji S, Venkateshwarlu K, Thota S, Venisetty PK, Venisetty RK. Prescribing pattern in coronary artery disease: a prospective study. Int J Pharm Res Rev. 2014;3(3):24-33. 
16. Tamilselvan T, Rajan H, Sabith T. A retrospective study of prescription pattern and cost analysis of selected drugs used in coronary artery disease and angioplasty patient. Inte $\mathrm{J}$ Rece Tren Sci Techno. 2016;21(1):09-12.

17. Shankar R, Partha P, Shenoy N. Prescribing patterns of drugs among patients admitted with cardiovascular disorders in the internal medicine ward: prescribing patterns in inpatients. Inte J Inter Med. 2000;3(1):1-5.

18. Sandozi T, Nausheen F. Drug utilization study in ischemic heart diseases associated with diabetes and hypertension. Int J Pharma Bio Sci. 2010;1(3):-4.
19. Christian RP, Rana DA, Malhotra SD, Patel VJ. Evaluation of rationality in prescribing, adherence to treatment guidelines, and direct cost of treatment in intensive cardiac care unit: a prospective observational study. Indian J Crit Care Med. 2014;18(5):278-84.

Cite this article as: Sawant MP, Padwal SL, Jadhav RR, Pise HN, Shinde R. Study of drug prescription pattern in ischemic heart disease patients. Int J Basic Clin Pharmacol 2019;8:1473-8. 